\title{
Chemical Analysis of Organic Fertilizers
}

\author{
Veen H.K.Y.W., Deraniyagala S.P., Cooray P.L.A.T.* \\ Department of Chemistry, University of Sri Jayewardenepura, Sri Lanka \\ *atcooray@sjp.ac.lk
}

\begin{abstract}
Organic fertilizers are materials with natural origin that is added to soil in order to supply essential nutrients to plants. Organic farming has become a popular trend in Sri Lanka. The idea of establishing quality standards to assist improvement of organic fertilizer products in terms of nutrition levels has been slowly evolving for the last few years. But even now quality of municipal solid waste (MSW) based and commercial fertilizers are not examined closely for their quality. This study was conducted using 9 organic fertilizer samples to obtain a chemical evaluation on different types of commercial organic fertilizers and municipal solid waste(MSW) based organic fertilizers. Average total $\mathrm{P}_{2} \mathrm{O}_{5}$ content and average total $\mathrm{N}$ content of each sample was determined by molybdovanadophosphate colorimetric method and kjeldahl method respectively. Average total $\mathrm{K}_{2} \mathrm{O}$ was determined using standard methods. Each digestion took 6 hours for completion. Samples were triplicated in $\mathrm{P}_{2} \mathrm{O}_{5}$ determination while samples were duplicated for other analysis.According to SLS 1246: 2003, standards for total $\mathrm{N}, \mathrm{P}_{2} \mathrm{O}_{5}$, and $\mathrm{K}_{2} \mathrm{O}$ are 1.0,0.5, and 1.0respectively. Total average $\mathrm{P}_{2} \mathrm{O}_{5}$ values of samples were in the range of 0.5-4.0 in terms of average w/w percentage. Most average $\mathrm{P}_{2} \mathrm{O}_{5}$ levels were below 1 . Average total $\mathrm{N}$ content of samples were above the standard requirement. Most average $\mathrm{K}_{2} \mathrm{O}$ values were below 1 lying in the range of 0.3-2.All the samples satisfied the requirements of the Sri Lankan standards for compost (SLS 1246: 2003)in terms of total $\mathrm{P}_{2} \mathrm{O}_{5}$ for total $\mathrm{N}$; however, $\mathrm{K}$ content of some samples were below the SLS requirement. It should be noted that for most of the samples, SLS standard for $\mathrm{P}_{2} \mathrm{O}_{5}$ was satisfied only at the lower end. Therefore, the analyzed organic fertilizers may not be a good source of K and P. Since organic fertilizers are heterogenic, it is required to analyze more replicate to obtain accurate data. It is recommended to analyze more replicate to obtain more accurate $\mathrm{N}, \mathrm{P}$ and $\mathrm{K}$ composition data to reacha solid conclusion about their quality.
\end{abstract}

Keywords: Organic fertilizers, NPK content 